\title{
Tetralogy of Fallot and Aortic Coarctation. A Rare Association
}

\author{
Renata Cristina de Santana, Vitor Coimbra Guerra, Nana Miura Ikari, Munir Ebaid
}

\author{
São Paulo, SP - Brazil
}

A two-year-old child with tetralogy of Fallot (TF) associated with coarctation of the aorta (CoAo) was referred to our institution for investigation of a cardiac murmur and cyanosis that had existed since the child's first days of life. In the physical examination, arterial hypertension in the upper limbs and reduction of pulses in the lower limbs were detected. The laboratory examinations confirmed the diagnosis of TF and CoAo. The patient underwent surgery for total correction and had a good clinical outcome.

Tetralogy of Fallot (TF) is considered the most common cyanotic malformation, with an incidence of $9.7 \%$ of all congenital heart disease ${ }^{1}$. It consists of a defect of the ventricular septum, pulmonary stenosis, dextroposition of the aorta, and right ventricular (RV) hypertrophy, which is secondary to its main characteristic, the anterior deviation of the infundibular septum.

Coarctation of the aorta (CoAo) is also a common cardiovascular malformation, responsible for $5 \%$ to $8 \%$ of all congenital heart diseases ${ }^{2,3}$. The classical clinical signs include hypertension in the upper limbs with a difference in pulse and pressure in relation to the lower limbs, and cardiac murmur. The association of these two anomalies is rare. Few cases have been reported in the literature ${ }^{4,5}$; therefore, this case has special interest.

\section{Case report}

The patient is a two-year-old child, born and raised in São Paulo, who was referred to the outpatient care unit of congenital heart diseases of INCOR, so that the cause of a cardiac murmur and cyanosis could be investigated. The child was on $2 \mathrm{mg} / \mathrm{kg} / \mathrm{day}$ of propranolol. The parents also reported that the child experienced dyspnea and frequently squatted during physical exercises.

The physical examination revealed the blood pressure (BP) to be $145 / 70 \mathrm{mmHg}$ in the upper limbs and the systolic blood pressure (SBP) to be $70 \mathrm{mmHg}$ in the lower limbs, with a reduction of the distal pulses. There was mild precordial

Instituto do Coração do Hospital das Clínicas - FMUSP

Mailing address: Renata Cristina de Santana - Rua Jaguaribe, 252/804 - 01224-000

- São Paulo, SP - Brazil bulging with systolic thrill at the third and fourth left intercostal spaces, and an ejecting systolic murmur $3+/ 4+$ along the left sternal border to the left infraclavicular region. There was also well-marked cyanosis of the perioral region and of the nail bed, intensified by crying and physical exercise.

The electrocardiogram revealed sinus rhythm with RV overload. The vectorcardiogram also showed RV hypertrophy (fig. 1). The chest roentgenogram revealed moderate cardiomegaly and reduction of pulmonary vascularity. The hemoglobin level was $16 \mathrm{mmHg} / \mathrm{dL}$, the hematocrit value $50 \%$, and the oxygen saturation in room temperature $88 \%$.

Two-dimensional echocardiogram confirmed the diagnosis of TF (with infundibular and valvar pulmonary stenosis of significant hemodynamic repercussion and pressure gradient between RV and pulmonary trunk of $75 \mathrm{mmHg}$ ) and CoAo (local gradient of $23 \mathrm{mmHg}$ ). Cardiac catheterization was performed revealing the abnormalities of this combination (fig. 2).

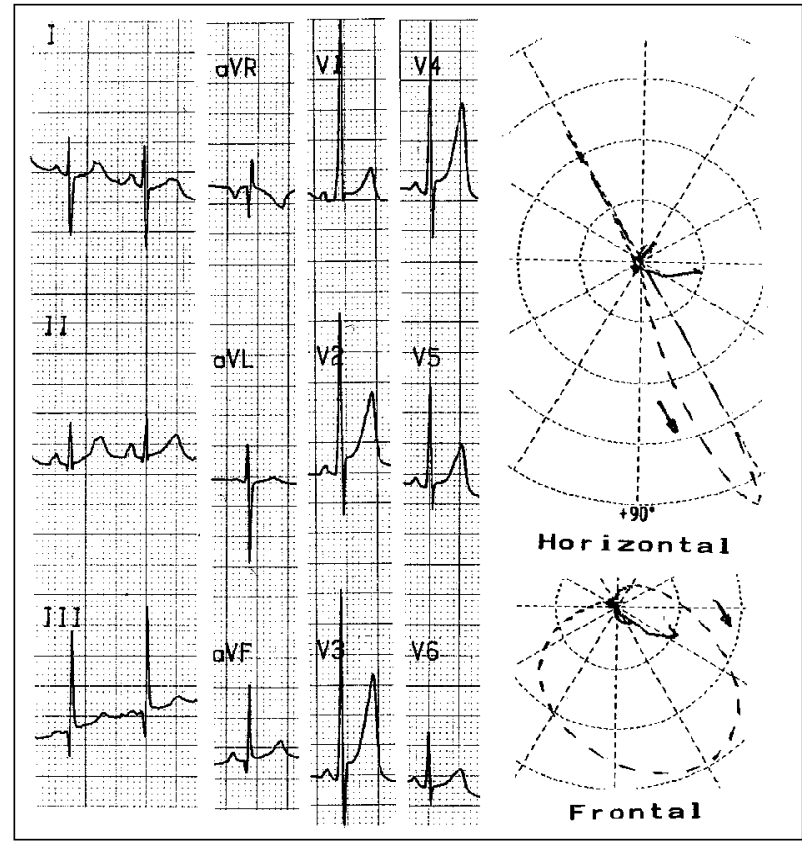

Fig. 1 - Electro and vectorcardiogram revealing right ventricular hypertrophy with the presence of left potentials. This is evidenced by the anticlockwise rotation of the QRS loop in the horizontal plane, due to the coarctation of the aorta. 


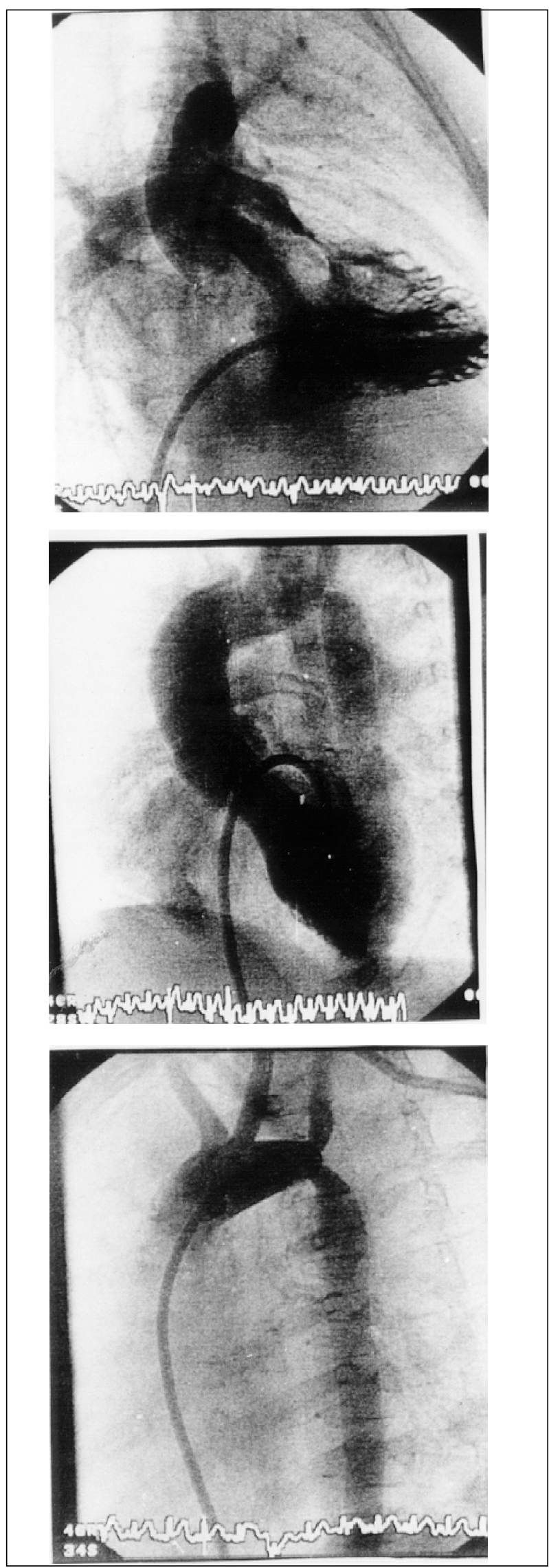

Fig. 2 - Right ventriculography showing the clear valvar infundibular stenosis and the hypertrophy of this chamber. The left ventriculography reveals the left-right flow through the ventricular septal defect, and the aortography shows the CoAo.
When the child was two years and two months of age, total surgical correction was performed with resection and termino-terminal anastomosis of the CoAo; resection of the infundibular stenosis and closure of the ventricular septal defect (VSD) with a patch of bovine pericardium were performed; enlargement of the RV outflow tract, with opening of the pulmonary ring and placement of a number 12 unicuspid was also done. The child had an uneventful postoperative outcome and by the time he was discharged, the AP levels were normal. Currently, the child is being followed up in the out patient care unit and is doing well.

\section{Discussion}

TF is important not only because of its incidence but also because of the severity of its symptoms and the effectiveness of the surgical correction. Usually the septal defect is large, perimembranous and subaortic, resulting from mal alignment of the infundibular septum with the rest of the muscle septum. The pulmonary stenosis is infundibularannular, with or without a valvar or supravalvar component, and with secondary RV hypertrophy. The conducting system and atrioventricular node are normally located and coronary anomalies are not uncommon. Cyanosis and hypoxemia characterize the clinical presentation because the reduction of the pulmonary blood flow due to obstruction of the RV outflow tract is the main hemodynamic abnormality. Hypoxic spells characterized by severe cyanosis accompanied by abnormal respiration and alteration in the level of consciousness can occur, especially in the morning and after physical exercises. The squatting position is often assumed. Children feel comfortable in this position, which increases pulmonary venous return and oxygen arterial saturation.

In the CoAo, the variety of symptoms depends on the way of presentation. In children (usually infants) with congestive heart failure, we find pallor, irritability, respiratory distress (tachycardia, dyspnea), hepatomegaly, and even edema of the limbs. A difference in cyanosis can be observed between the upper and lower limbs, depending on the existence of a patent ductus arteriosus at the coarctation level or just after it. The most pathognomonical clinical finding is the discrepancy in the pulse and SBP between the upper and lower limbs. Surgical correction performed before the age of three years minimizes the incidence of recoarctation, and the risk of sudden death in adult life decreases considerably when the correction is made during the school age years ${ }^{2}$. Currently, with the development of new surgical techniques, the results have been more encouraging, even when surgery is performed on neonates or infants.

In this reported case, cyanosis was severe despite the CoAo, which would tend to increase the pulmonary flow due to the increase of the systemic resistance, similar to what occurs in the squatting position, resulting from the severe degree of obstruction in the RV outflow tract.

The combination of TF and CoAo is rare. In this particular case, the association is difficult to explain by means of 
the hemodynamic theory, because this patient had no obstructive lesion at the left ventricle outflow tract that could restrict the blood flow at the isthmic portion of the aorta. The ductal flow through the pulmonary artery could have been increased during fetal life with a concomitant reduction of the transvalvar aortic flow, if the ovalis foramen had been restricted even in the presence of TF. This hypothesis would indicate that the pulmonary obstruction was not significant during fetal life ${ }^{4}$. Another hypothesis is that independently from the degree of subpulmonary obstruction, the RV can empty into the left ventricular and into the aorta overriding, through the non-restrictive VSD, therefore keeping a major flow through the ascending aorta rather than the descending aorta ${ }^{5}$. Another suggestion would be the external compression of the aorta during fetal life. It has also been proposed that the presence of the left superior vena cava is associated with the development of $\mathrm{CoAo}^{3}$.

There are four possibilities of surgical treatment for this combination: to repair first and separately the TF or the CoAo, to repair concomitantly with coartectomy and pulmonary-systemic shunt (Blalock Taussig) or coartectomy with correction of the intracardiac defects ${ }^{5,6}$. This last option seems to be the most successful in children because it reduces the number of interventions and exposure to surgical and postoperative risks, besides providing total correction of the problem.

In conclusion, the cause of this combination of defects is difficult to explain. Independent of the rarity of the association, the diagnosis of CoAo is still clinical and can be performed in a routine pediatric consultation through a complete cardiovascular physical examination.

\section{References}

1. Zuberbuhler Jr - Tetralogy of Fallot. In: Adams IH, Emmanouilides GC, Rimenschneider TA, eds - Moss' Heart Disease in Infants, Children, and Adolescents; $5^{\text {th }}$ ed. Baltimore: Williams \& Wilkins, 1995: 998-1017.

2. Ing FF, Starc TJ, Griffiths SP, Gersony WN - Early diagnosis of coarctation of the aorta in children: a continuing dilemma. Pediatrics 1996; 98: 378-82.

3. Beekman RH - Coarctation of the aorta. In: Adams FH, Emmanouilides GC, Riemenschneider TA, eds - Moss' Heart Disease in Infants, Children, and Adolescents; $5^{\text {th }}$ ed. Baltimore: Williams \& Wilkins, 1995: 1111-33.
4. Elami A, Rein AJ, Prenimger TJ, Milgater E - Tetralogy of Fallot, absent pulmonary valve, partial anomalous pulmonary venous return and coarctation of the aorta. Int J Cardiol 1995; 52: 203-6.

5. Bullaboy CA, Derkac WM, Johnson DH, Jennings RB Jr - Tetralogy of Fallot and coarctation of the aorta: successful repair in an infant. Ann Thorac Surg 1984; 38 : 400-1.

6. Praagh RN - Tetralogy of Fallot (S, D, I): a recently discovered malformation and its surgical management. Ann Thorac Surg 1995; 60: 1163-5. 